\title{
Representações sociais da espiritualidade de quem vive com Aids: um estudo a partir da abordagem estrutural ${ }^{1}$
}

\author{
Social representations about spirituality of people who lives with aids: un study \\ according to structural approach
}

\author{
Antonio Marcos Tosoli Gomes ${ }^{2}$ \\ Sergio Correia Marques ${ }^{3}$ \\ Themistoklis Apostolidis ${ }^{4}$ \\ Virginia Paiva Figueiredo Nogueira ${ }^{5}$ \\ Karen Paula Damasceno dos Santos Souza ${ }^{6}$ \\ Luiz Carlos Moraes França ${ }^{7}$
}

\begin{abstract}
RESUMO: O objetivo do estudo é analisar os conteúdos que integram a representação social da espiritualidade entre pessoas que vivem com HIV/Aids assistidas no serviço de atendimento especializado de um hospital universitário no Rio de Janeiro. É um estudo descritivo, de natureza qualitativa, apoiado na teoria do núcleo central das representações sociais, realizado no período de março a setembro de 2015 com 166 pacientes assistidos no Serviço de Atendimento Especializado em aids do referido hospital. Utilizou-se a técnica de evocação livre de palavras ao termo indutor espiritualidade na coleta de dados e o questionário sociodemográfico para caracterização dos participantes. Os dados do questionário foram organizados no software excel e os conteúdos das evocações foram tratados pela técnica do quadro de quatro casas e analisados à luz dos pressupostos da teoria do núcleo central. Os resultados evidenciaram que houve predomínio de pessoas do sexo masculino com idade entre 41 a 60 anos. Declararam-se, por ordem de frequência, católicos, espíritas e evangélicos, sendo que 30 indivíduos afirmaram não professar nenhuma religião. Os elementos que compõem o núcleo central da representação são ter fé, Deus e religião, sendo que ter fé e Deus são os possíveis elementos centrais pelos fortes laços que estabelecem com os demais termos presentes na representação. Conclui-se que a representação da espiritualidade está organizada em dois polos, o divino e o humano, que têm uma relação direta ou é mediado pela religião.
\end{abstract}

Palavras-chave: espiritualidade; HIV; Aids; enfermagem; religião.

\footnotetext{
1 Financiamento: Conselho Nacional de Desenvolvimento Científico e Tecnológico/Edital Universal - Processo número 483300/2013-6; Fundação Carlos Chagas Filho de Amparo à Pesquisa do Estado do Rio de Janeiro/Edital Jovem Cientista do Nosso Estado - Processo número E_23/2013 - Jovem Cientista do Nosso Estado.

2 Professor Titular do Departamento de Enfermagem Médico-Cirúrgica e do Programa de Pós-graduação em Enfermagem da Faculdade de Enfermagem da Universidade do Estado do Rio de Janeiro. Líder do Grupo de Pesquisa "Espiritualidade/Religiosidade no contexto do Cuidado de Enfermagem e Saúde: Produção Discursiva e Representações Sociais - UERJ" - Rio de Janeiro, RJ, Brasil. E-mail: mtosoli@gmail.com.

3 Professor Adjunto do Departamento de Fundamentos de Enfermagem e do Programa de Pós-graduação em Enfermagem da Faculdade de Enfermagem da Universidade do Estado do Rio de Janeiro - Rio de Janeiro, RJ, Brasil.

${ }^{4}$ Diretor do Laboratório de Psicologia Social da Aix Marseille Université, LPS EA 849, 13621 - Aix en Provence, France.

${ }^{5}$ Doutoranda do Programa de Pós-Graduação em Enfermagem da Faculdade de Enfermagem da Universidade do Estado do Rio de Janeiro. Membro do Grupo de Pesquisa "Espiritualidade/Religiosidade no contexto do Cuidado de Enfermagem e Saúde: Produção Discursiva e Representações Sociais - UERJ" - Rio de Janeiro, RJ, Brasil.

${ }^{6}$ Mestranda do Programa de Pós-Graduação em Enfermagem da Faculdade de Enfermagem da Universidade do Estado do Rio de Janeiro. Membro do Grupo de Pesquisa "Espiritualidade/Religiosidade no contexto do Cuidado de Enfermagem e Saúde: Produção Discursiva e Representações Sociais - UERJ" - Rio de Janeiro, RJ, Brasil.
}

7 Mestrando do Programa de Pós-Graduação em Enfermagem da Faculdade de Enfermagem da Universidade do Estado do Rio de Janeiro. Membro do Grupo de Pesquisa "Espiritualidade/Religiosidade no contexto do Cuidado de Enfermagem e Saúde: Produção Discursiva e Representações Sociais - UERJ" - Rio de Janeiro, RJ, Brasil. 


\begin{abstract}
: the objective of the study is to analyze the contents that integrate the social representation of spirituality among people living with HIV/AIDS assisted in the specialized attention service of a university hospital in Rio de Janeiro. It is a descriptive and qualitative study based on the central core theory of social representations, carried out in the period from March to September 2015 with 166 patients assisted in the Specialized Attention Service in AIDS of the referred hospital. For data collection, it was used the sociodemographic questionnaire and the technique of words evocation to the term inducer spirituality in the data collection. The data of questionnaire were organized in excel software and the contents of the evocations were treated by the four-frame technique and analyzed considering the assumptions of the central core theory. The results showed a predominance of males aged between 41 and 60 years. They were declared, in order of frequency, Catholics, Spiritists and Evangelicals, and 30 individuals stated that they did not profess any religion. The elements that make up the central nucleus of representation are faith, God and religion, and to have faith and God are the possible central elements because of the strong ties they establish with the other terms present in the representation. It was concluded that the representation of spirituality is organized in two poles, the divine and the human, that have a direct relationship or is mediated by religion.

Keywords: spirituality; HIV; Aids; nursing; religion.
\end{abstract}

\title{
Introdução
}

A espiritualidade expressa o sentido profundo do que se é e se vive, assumindo o corpo e permitindo ao homem ultrapassar a dimensão biológica e emocional de suas vivências (Valle, 2005). Remete a uma relação pessoal com o transcendente, algo extrafísica, que já foi chamado de sobrenatural. Assim, a espiritualidade refere-se a algo mais genérico que, inclusive, pode incluir a religião (Borges, Santos \& Pinheiro, 2015).

Essa dimensão, assim como a religiosa encontram-se, historicamente para a maioria do povo brasileiro, no centro da vida cotidiana. De acordo com alguns teóricos (Valle, 2005; Ribeiro, 1995), o transcendente e o divino não são uma instância abstrata para os latinoamericanos como um todo. São uma realidade existencial quase tangível nas mais variadas situações, gerando atitudes e conformando decisões que possuem relevância para as diversas áreas da vida humana, inclusive a saúde.

No que tange à área da saúde, há uma conformação multifacetada, uma vez que a adesão ou não ao tratamento e práticas pessoais de cuidado podem ser fortemente influenciadas pelo exercício da espiritualidade (Koenig, Pargament \& Nielsen, 1998). Nesse sentido, "as crenças sobre religião e espiritualidade podem influenciar o modo como pacientes e profissionais de saúde percebem a saúde e a doença e como interagem com os outros" (Borges et al., 2015; Silva, 2010; Moreira-Almeida \& Lucchetti, 2016). Por outro lado, a espiritualidade pode ser uma estratégia empregada para o enfrentamento de situações adversas, promovendo o aumento do senso de propósito e significado da vida, fatores associados ao aumento da resistência ao estresse relacionado às doenças (Rocha \& Ciosak, 2014).

No que se refere às pessoas que vivem com HIV/Aids (PVHA), a espiritualidade ganha importância através do encontro de sentido da vida e de razão para viver após o diagnóstico, entre outros tantos aspectos. Ou seja, a vivência da doença não é dada apenas pela patologia em si, mas também pela representação desta para o sujeito. A partir desta representação e através dela é que as pessoas conferem significado à doença e buscam um sentido para a vida (Silva, 2010).

Alguns estudos (Meneghel et al., 2008; Prado et al., 2004; Faria \& Seidl, 2006) desenvolvidos com esta temática têm evidenciado que a espiritualidade é uma estratégia positiva para o enfrentamento da aids e das alterações biopsicossociais que a doença acarreta na vida de PVHA. Esses mesmos estudos mostram que os enfermeiros têm 
reconhecido a importância da dimensão espiritual e religiosa como parte do cuidado de enfermagem aos usuários dos serviços de saúde, porém de forma tímida no contexto de vida das PVHA.

A Teoria das Representações Sociais tem sido muito utilizada para tentar explicar a problemática social e o enfrentamento cotidiano da aids (Moreira-Almeida \& Lucchetti, 2016). Portanto, acessar as representações sociais da aids torna-se um caminho para a compreensão da espiritualidade, que pode interferir nas atitudes e nas práticas do grupo social (Herzlich, 1991), seja ela dos portadores da síndrome ou dos profissionais de enfermagem.

A partir do exposto, desenvolveu-se o presente estudo que tem por objetivo: analisar os conteúdos que integram a representação social da espiritualidade entre PVHA assistidas no serviço de atendimento especializado (SAE) de um hospital universitário no Rio de Janeiro. Espera-se fomentar a produção do conhecimento acerca da espiritualidade no contexto da saúde e contribuir na sua interface com a prática do cuidado em enfermagem, em especial para o grupo de portadores do HIV/Aids.

\section{Método}

Trata-se de um estudo descritivo com abordagem qualitativa apoiado na teoria do núcleo central (TNC) das representações sociais, no contexto da psicologia social (Abric, 2003; Sá, 2015). Para o propositor da teoria, a representação "é constituída de um conjunto de informações, de crenças, de opiniões e de atitudes a propósito de um dado objeto social (Abric, 2003, Ratzinger, 1970). Nessa perspectiva, a representação se organiza de uma forma específica com elementos que formam um núcleo central, que dão significado à representação, tendo ao seu redor elementos periféricos, que são mais acessíveis e mais concretos, exercendo as funções de concretização, regulação e defesa desse núcleo (Abric, 2003).

O estudo integra o projeto intitulado "A espiritualidade e a religiosidade em pessoas que vivem com HIV/Aids e suas interfaces com as representações da síndrome: construções simbólicas, práticas sociais e cuidado de enfermagem", aprovado pelo Comitê de Ética em Pesquisa da Universidade do Estado do Rio de Janeiro com o parecer no 699.220/2014.

O campo da pesquisa foi um serviço ambulatorial especializado em HIV/Aids (SAE) de um hospital universitário estadual situado no município do Rio de Janeiro. Participaram do estudo 166 pacientes em tratamento no referido SAE, com idade superior a 18 anos. Não participaram aqueles que não se encontravam em condições de saúde adequadas.

Os dados foram coletados nos meses de março a setembro de 2015 , por meio das técnicas de questionário e de evocações livres de palavras, para a obtenção, respectivamente, dos dados sóciodemográficos e dos conteúdos semânticos da representação. A técnica de evocação possibilita obter os conteúdos de forma rápida e objetiva, diferenciando-se de outras técnicas de coleta de dados (Oliveira \& Gomes, 2015).

Aplicou-se inicialmente a técnica de evocação solicitando aos participantes, individualmente, que falassem cinco palavras ao termo indutor "espiritualidade" e em seguida que preenchessem o questionário.

Os dados sociodemográficos foram registrados na planilha do software Excel e depois organizados em tabelas, com frequências absolutas e relativas, e os dados das evocações foram organizados em um corpus e analisado pela técnica do Quadro de Quatro Casas (Vergès, 2002) com o auxílio do software EVOC 2005. Esse programa calcula a frequência de ocorrência de cada palavra evocada e sua média ponderada de ocorrência em função da 
ordem de evocação, além da média das ordens médias ponderadas do conjunto das palavras evocadas, culminando com a formação do Quadro de Quatro Casas (Oliveira \& Gomes, 2015).

No quadro, os conteúdos ficam distribuídos em quatro quadrantes distinguindo-se em elementos centrais e elementos periféricos. Os primeiros, situados no quadrante superior esquerdo, constituem o possível núcleo central da representação, sendo os elementos que dão significado à representação; os periféricos se organizam em torno do núcleo central sendo os componentes mais acessíveis e concretos da representação (Abric, 2003). A partir desta organização e à luz da TNC os conteúdos foram analisados.

Para verificar a quantidade de laços ou conexão existentes entre os elementos identificados como participantes da representação social em tela, aplicou-se a técnica de análise de similitude (Pecora \& Sá, 2008). Essa técnica averigua a quantidade de conexões que um elemento mantém com os outros elementos evocados, através do cálculo dos índices de similitude entre os elementos mais frequentemente evocados resultando em uma árvore máxima, que sintetiza graficamente o conjunto das conexões existentes entre os elementos da representação social do grupo (Pecora \& Sá, 2008; Pontes, Oliveira \& Gomes, 2014).

\section{Resultados}

No grupo estudado, composto por 166 participantes, 101 (60,8\%) são do sexo masculino e 65 (39,2\%) do sexo feminino, sendo que a faixa etária predominante é a de 41 a 60 anos com $95(57,3)$ PVHA. Em relação à religião, $62(37,3 \%)$ se declararam católicos, 42 (25,3\%) espíritas, 32 (19,3\%) evangélicos e 30 (18,1\%) afirmaram não professar nenhuma religião. A maioria $(75,9 \%)$ afirmou participar de atividades religiosas antes de conhecer a soropositividade para o HIV, sendo que 39 (23,5\%) não desenvolviam esse tipo de atividade. Após o diagnóstico do HIV houve um acréscimo de $2,4 \%$ no grupo que afirmou participar de atividades religiosas.

Quanto ao resultado das evocações livres, o software EVOC versão 2005 contabilizou 700 palavras evocadas, sendo 233 diferentes. Considerando que se adotou como frequência mínima quatro, encontrou-se a frequência média igual a 14, a frequência mínima oito e a média das ordens médias de evocação (O.M.E) igual a 2,7, numa escala de 1 a 5 . A análise combinada desses dados resultou na organização dos conteúdos apresentada na Figura 1.

\begin{tabular}{|l|l|c|c|l|l|l|}
\hline \multicolumn{3}{|c|}{ O.M.E. < 2,70 } & \multicolumn{3}{c|}{ O.M.E $\geq 2,70$} \\
\hline Freq. méd & Termo evocado & freq & O.M.E. & Termo evocado & freq & O.M.E. \\
\hline \multirow{3}{*}{$\geq 14$} & Ter-fé & 67 & 2,00 & Amor & 45 & 3,02 \\
& Deus & 56 & 1,41 & Paz & 24 & 3,12 \\
& Religião & 21 & 1,61 & & & \\
\hline \multirow{3}{*}{$<14$} & & 12 & 2,33 & Esperança & 11 & 3,09 \\
& Jesus & 10 & 2,70 & Confiança & 9 & 2,88 \\
& Força & 10 & 2,70 & Caridade & 9 & 3,22 \\
& Vida & 8 & 1,87 & Saúde & 9 & 3,22 \\
& Tudo & 8 & 2,25 & Conforto & 8 & 3,25 \\
& Crença & & & Família & 8 & 3,25 \\
& & & Espírito Santo & 8 & 3,50 \\
\end{tabular}

Figura 1 - Quadro de quatro casas dos conteúdos evocados pelas pessoas que vivem com HIV/Aids ao termo indutor "Espiritualidade". Rio de Janeiro, RJ, Brasil, 2015. ( $n=166$ participantes). 
O quadro de quatro casas evidencia que no quadrante superior esquerdo estão os termos ter-fé, Deus e religião que, pela combinação dos critérios de frequência (maior que 14 ) e de ordem média de importância $(<2,7)$ compõem o provável núcleo central da representação social do grupo. Considerando que o núcleo central ou núcleo estruturante da representação possui duas funções importantes, esses termos exercem a função geradora, pois geram o significado básico da representação; e a função organizadora, pois determinam a organização global de todos os elementos da representação. Constituem a parte dura da representação, ou seja, mais estável e, portanto, que mais vai resistir as mudanças (Abric, 2003; Sá, 2015).

Cabe destacar que nem todos os elementos que se encontram nesse quadrante são necessariamente centrais, contudo, dado o caráter aproximativo da técnica, alguns elementos presentes em outros quadrantes podem ser, também, centrais na representação (Abric, 2003). Os demais termos presentes no quadro, que estão no entorno do núcleo central, constituem o sistema periférico da representação. Esse sistema expressa as experiências e histórias individuais, comporta a heterogeneidade do grupo e suas contradições e é evolutivo e sensível ao contexto imediato dos indivíduos (Sá, 2015).

Analisando-se o sistema periférico, verifica-se que no quadrante inferior esquerdo, denominado zona de contraste, estão posicionados os termos com baixa frequência, porém considerados importantes pelos participantes, haja vista que foram mais prontamente evocados (O.M.E. < 2,7). São eles: Jesus, força, vida, tudo e crença. No quadrante superior direito, denominado primeira periferia, estão os termos amor e paz, que também tiveram frequência alta, porém não foram tão prontamente evocados (O.M.E $>2,7$ ) como os termos anteriormente mencionados. É neste quadrante que estão dispostos os elementos periféricos mais importantes da representação e que, via de regra, reforçam os elementos centrais.

No quadrante inferior direito (segunda periferia), estão os seguintes termos: esperança, confiança, caridade, saúde, conforto, família e espírito santo, que são menos frequentes e foram mais tardiamente evocados, e por isso considerados menos importantes para a determinação do significado da representação (Abric, 2003; Oliveira \& Gomes, 2015). Em relação à análise de similitude, a conexidade entre os elementos está representada na árvore máxima, exposta na Figura 2.

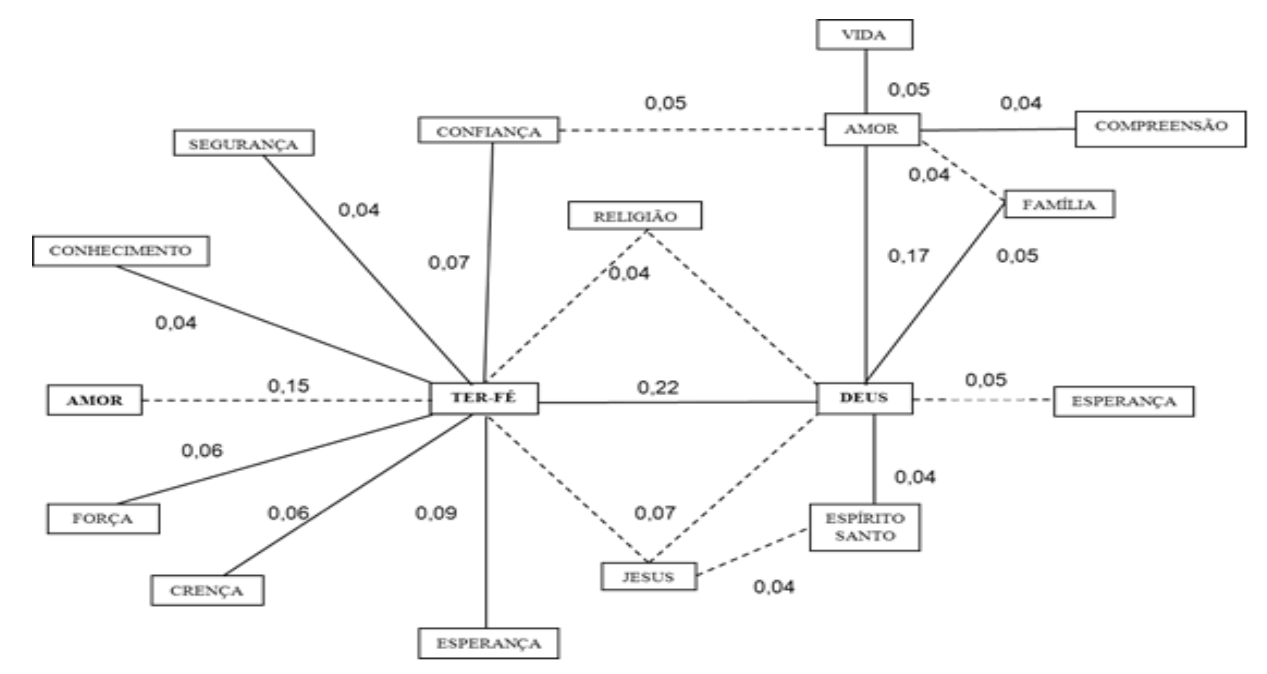

Figura 2 - Árvore máxima de similitude das evocações das PVHA ao termo indutor espiritualidade. Rio de Janeiro, RJ, Brasil, 2015 ( $n=103)$. 
Constata-se na Figura 2 três blocos temáticos associados que irradiam sentido à representação da espiritualidade: ter-fé, Deus e amor. O termo que mais fez conexões na árvore máxima foi ter-fé, já apontada como central no quadro de quatro casas. Este termo estabeleceu conexão com outros dez presentes na representação do grupo, sendo que manteve os maiores índices de similitude, por ordem de grandeza, com os termos Deus $(0,22)$, amor $(0,15)$, esperança $(0,09)$, Jesus $(0,07)$ e confiança $(0,07)$. 0 termo Deus, também central, foi o segundo termo em estabelecimento de conexões, tendo realizado sete, sendo os maiores índices de similitude com os elementos ter-fé e amor. O terceiro termo que se destaca pelo número de conexões é o termo amor, fazendo seis ligações, também mantendo índice de similitude elevado com os termos Deus e ter-fé.

A análise de similitude não permite confirmar a centralidade dos elementos de uma representação na perspectiva estrutural, porém é considerada um segundo indicador da provável participação dos elementos no núcleo central (Pecora \& Sá, 2008; Pontes et al., 2014). Nesse sentido, no resultado precedente, os termos ter-fé e Deus, já supostamente centrais, reforçam a possibilidade da centralidade pela quantidade de conexões e fortes laços estabelecidos com outros elementos. Quanto ao termo amor, presente na primeira periferia do quadro (Figura 1), pode-se supor que apresenta uma tendência de migrar para o núcleo central.

Por outro lado, o termo religião, que é central no quadro de quatro casas, tem apenas duas ligações com baixo índice de similitude, afastando-o da hipótese de ser um elemento central da representação.

\section{Discussão}

A estrutura da representação social da espiritualidade para pessoas que vivem com o HIV/Aids em um ambulatório especializado comporta dois polos principais que, por sua vez, se desdobram em questões práticas cotidianas no enfrentamento do processo de diagnóstico e de vivência do vírus e/ou da síndrome. Estes dois polos podem ser caracterizados, por um lado, pelo ser superior, pela transcendência e por uma suprema alteridade denominada, pelo senso comum, de Deus e, por outro, pela ação humana de ter fé como chave que possibilita a relação com este divino. Este divino, como pontuado, caracteriza-se por ser uma alteridade que não pode ser apreendida de outra forma, a não ser pela decisão humana de dar um passo em sua direção, uma vez que se encontra para além da objetividade da ciência e maior do que a subjetividade humana, se apresentando como estruturador de sentido na constituição da vida e no enfrentamento da doença e da morte.

Diferentes autores (Moreira-Almeida, Lucchetti, 2016; Koenig, 2012) apontam que a espiritualidade se constitui, inclusive nos resultados das pesquisas da área da saúde, como uma relação com o sagrado e o transcendente, no domínio do espírito, do extrafísico e do não material. Estes autores apontam ainda que o conceito de espiritualidade não pode ser considerado com algo inespecífico, uma vez que deve ser distinguido de questões como valores, humanismos, moral e saúde mental, sendo definido como o divino, intimamente conectada com o sobrenatural e o místico, assim como com a própria religião organizada, embora seja anterior à própria religião (Koenig, 2012).

Esta dimensão cognitiva da representação mostra-se bem delimitada em sua estrutura, especialmente na tradução do divino e do transcendente cristão, uma vez que ao redor do genérico nome Deus estão ligadas as míticas figuras de Jesus e do espírito santo, o que completaria um dos dogmas centrais da cristandade, a denominada Trindade. Como 
suprema Divindade cristã, de cunho essencialmente comunitária, a trindade se apresenta como um profundo mistério de relação entre si, em que cada pessoa divina permanece com suas próprias identidades, mas está completamente interpenetrada com as demais, a ponto de, no contexto e na força deste encontro, ficou impossível, do ponto de vista teológico, não transbordar seu amor e poder, gerando toda a criação à sua imagem e semelhança (Betto, 2007).

Entre os dois polos, a estrutura representacional aponta, ainda, uma passagem que permite a ligação profunda entre o transcendente, o totalmente outro na linguagem da filosofia, com o ser humano, que é aquele que pode portar a fé e ressignificar a vida e o mundo a partir deste olhar. Na estrutura supracitada esta ligação está evidente através dos léxicos religião e Jesus, além da própria relação direta entre Deus e a fé. Neste último caso, da relação direta, a representação social se organiza a partir de seu enraizamento na experiência humana frente ao divino, onde este se auto comunica, ou melhor, quando há compreensão desta autocomunicação sem outras mediações. De um modo geral, este fenômeno é muito comum em fundadores de religiões que trazem novidades existenciais, sociais e culturais a partir de uma nova forma de compreender e de viver esta relação (Eliade, 2011).

Ao lado desta situação complexa, completa e direta de uma autocomunicação divina ou da compreensão humana desta comunicação com forte impacto na sociedade e na história, como o foi na fundação do Cristianismo e do Islamismo, existe hoje uma tendência a uma valorização de uma relação cada vez mais sem mediações entre o humano e o divino, como pode ser observado na multiplicação de grupos religiosos que possuem esta atitude como fundamental ao exercício da fé (Souza, 2004; Dantas \& Rodrigues, 2012). Observa-se, então, a presença do transcendente em todas as dimensões da vida na medida em que esta é atravessada por este Deus que se interessa diuturnamente por cada detalhe da vida de seus fiéis. Mais ainda, esta relação direta torna-se dialética na mesma direção em que um mundo espiritual é descortinado na ausência da mediação da razão, da pessoa especializada de referência e do saber teológico crítico; o cotidiano torna-se, então, uma arena em que o bem e o mal, Deus e Lúcifer, anjos e demônios, santos e entidades negativas travam uma batalha pela vitória ou derrota temporal, ou de maneira ainda mais intensa: pela salvação ou perdição interna da pessoa (Hiebert, 2008).

Ao lado desta forte relação direta entre o ser humano e o divino presente na estrutura da representação social, possivelmente como fruto do avanço das igrejas evangélicas pentecostais e neopentecostais e do movimento carismático católico, ainda persiste a compreensão de que se necessita de mediações para uma melhor compreensão desta experiência. Neste sentido, as representações sociais destes pacientes trouxeram duas outras possibilidades de mediação, quais sejam, a religião e Jesus.

A religião, por sua vez, pode ser definida como um sistema que envolve crenças, práticas e rituais relacionados ao transcendente, ao mesmo tempo em que condensa, em si mesmo, um conjunto de crenças acerca da vida após a morte e de papéis sociais, culturais e devocionais dentro de um grupo sócio religioso. Trata-se, simultaneamente, de um sistema de crenças, práticas e símbolos que colaboram para a proximidade do sujeito com a divindade e a responsabilidade com os demais e a vida coletiva em uma comunidade (Koenig, 2012).

Caracteriza-se, ainda, por ser a institucionalização da experiência espiritual (MoreiraAlmeida, Lucchetti, 2016) e, por isto, acarreta segurança social e a possibilidade de perenização desta experiência, ao passo que oferece o risco de sua domesticação 
sociocultural nos quadros possíveis de uma determinada sociedade e/ou realidade. As Igrejas Cristãs ou as várias correntes do Budismo possivelmente não se configuraram, a longo dos séculos, como Cristo e Buda pensaram, respectivamente, mas foram elas que permitiram ao homem moderno ter contato com as proposições teóricas, práticas, devocionais e filosóficas destes homens (Silva, 2008).

$\mathrm{O}$ desafio de toda religião é traduzir, no âmbito dos quadros intelectuais, afetivos e subjetivos humanos uma carga de experiência que, na maioria das vezes, a razão não consegue comportar e nem oferecer sentido. A dialética entre a transcendência e a imanência, a potência divina e a fragilidade humana, a eternidade do divino e a fugacidade humana e a invulnerabilidade do transcendente e a vulnerabilidade ontológica do humano, dentre outras inúmeras relações binárias de oposição que poderíamos citar, torna a religião como uma mediação poderosa e ambígua. Este poder e esta intensidade centram-se na tensão existente entre os polos trabalhados pela religião: a eternidade e o poder absoluto (o polo divino) e o marcado temporalmente e à mercê de um poder externo (o polo humano) (Boff, 2002).

A outra mediação refere-se à figura de Jesus, símbolo fundamental para a construção e a perpetuação do que se convencionou chamar de ocidente. Este forte símbolo possui dois desdobramentos importantes: o primeiro relacionado à própria Igreja cristã, aprofundada no parágrafo anterior quando tratamos das religiões; a segunda, na figura do próprio Jesus. Pela tradição teológica cristã, católica e evangélica, a mediação entre o humano e o divino ganha status de excelência no rosto de um homem inicialmente desconhecido no oriente médio do século I, uma vez que, para esta construção teórica, é o próprio Deus que se coloca como pontífice desta relação ao se encarnar em um homem específico e se revelar ao mundo.

Esta proposição se estrutura ainda na ideia de que ele pagou a imensa dívida humana relativa à incomensurável falta cometida no início dos tempos. A vida e, em especial, a morte de Jesus é considerada como a mediação perfeita e a última aliança possível entre Deus e os homens. Para os cristãos - a quase totalidade dos sujeitos estudados -, Deus ganha um rosto e uma data histórica e a sua relação com os humanos somente pode fluir por este canal (Costa, 2011). Este fato é tão marcante que a controvérsia entre protestantes e evangélicos com os católicos é justamente pela possibilidade de ocultação desta mediação única e insubstituível.

A Igreja cristã, neste caso, possui o status de mediadora como prolongamento deste papel único de mediação de Jesus e isto resultou em uma construção teórica que legitimasse a sua ação sobreposta ao de seu considerado fundador histórico: a possibilidade da confissão auricular dos pecados e a consagração das espécies eucarísticas in persona Christi é um exemplo desta situação, em que se vê o sacerdote, mas não é ele que perdoa ou que consagra, mas sim o próprio Jesus (Dias, 2010).

Se a fé é algo bastante compreensível no senso comum, sua apreensão teórica tornase um pouco mais difícil e até mesmo escorregadia (Souza, Frizzo, Paiva, Bousso, Santos, 2015). Neste sentido, de toda uma literatura própria que trata a questão, interessa-nos apreender aquelas que possuem mais aderência à discussão da temática no contexto do presente artigo. Neste sentido, ter fé possui relação com a crença em algo maior do que as situações e a própria vida e que, de alguma maneira, este algo costura a existência humana de sentido e ânimo, mesmo nas piores situações (Frankl, 2007). Desta maneira, pode-se compreender que a fé implica em uma decisão humana em que há um ponto, no âmago da existência humana, que não é necessariamente objetivo, racional e visível, por isto toca as 
fronteiras do invisível e do intangível, tornando-o tangível como algo indispensável à própria existência (Ratzinger, 1970).

A fé necessariamente apresenta-se como um ato humano de se enraizar na realidade de maneira integral, dando sentido ao passado e esperança e paciência com relação ao futuro. Por isto, está intimamente associada ao sentido da existência e a um alinhavar global que permite compreender a existência sob uma ótica mais ampla e profunda do que a realidade mais imediata. Para as religiões, há, na fé, um sentido que não é somente produzido pelo humano em face das situações que lhe acometem, mas também um que é recebido deste transcendente e que não é controlado pelo racional, pela sociedade ou pela cultura, que, em função deste caráter transcendental, requer adesão ao que se considera como uma verdade que não pode ser ocultada ou ignorada (Ratzinger, 1970).

Pode-se compreender, dada a profundeza humana da fé de homens e mulheres concretos que vivem o enfrentamento do HIV e da síndrome, a construção de um raio de fortes significados, como esperança, crença, força, amor, conhecimento, confiança e segurança ao redor do léxico fé. É o humano guiado por uma profundidade de si mesmo que, de alguma maneira, toca o infinito e ganha um sentido que está para além do que pode ser compreendido objetivamente, mas que o torna um ponto equidistante entre a profundidade de sua própria essência e o transcendente.

\section{Conclusões}

Conclui-se que a representação social da espiritualidade para pessoas que vivem com o HIV/Aids em um ambulatório especializado possui uma estrutura organizada em dois polos: o divino e o humano, que se encontram em uma relação direta ou mediado pela religião, que adquire um dos seus conceitos principais, qual seja, o de religação, e pela mítica figura do sumo pontífice, neste caso, o próprio Deus encarnado, como propõe a teologia cristã. 0 polo divino é objetivado pela imagem do próprio Divino em sua manifestação mais presente no senso comum (Deus) e o humano em uma dimensão representacional da prática, a da fé. Ao redor gravitam importantes sentimentos, ações e estruturas sociais que sofrem a benéfica influência do encontro entre estes polos.

Deve-se destacar que a estrutura representacional possui um conceito largo de espiritualidade, que inclui sentido para a vida, bem-estar, relações sociais e o estabelecimento de diálogo com a divindade. Não exclui, no entanto, a mediação da religião e nem a presença de figura mítica que também está ligada a uma estrutura religiosa determinada. Com isto, adota-se uma hipótese que deverá orientar o desenvolvimento de outros estudos, de que, na representação social deste grupo social, a espiritualidade abarca também a própria religião, sendo, portanto, mais ampla e abrangente do que esta.

Conclui-se ainda que este estudo demonstrou a importância da abordagem desta temática para que se possa entender suas práticas cotidianas, assim como dimensões de enfrentamento do processo diagnóstico e do viver com HIV/Aids. Os profissionais, ao conhecer a forma como a espiritualidade é reconstruída sócio-cognitivamente, tem a possibilidade de considerar seus elementos e sua estrutura no processo assistencial que desenvolvem com os pacientes. Por fim, ressalta-se a teoria das representações sociais como um importante instrumental teórico-metodológico para este tipo de estudo. 


\section{Referências}

Abric, J. C. (2003). A abordagem estrutural das representações sociais: desenvolvimentos recentes. In P. H. F. Campos \& M. C. S. Loureiro. Representações sociais e práticas educativas (pp. 37-57). Goiânia, GO: Ed. UCG.

Betto, F. (2007). A arte de semear estrelas. Rio de Janeiro, RJ: Rocco.

Boff, L. (2002). Experimentar Deus: a transparência de todas as coisas. Campinas, SP: Verus.

Borges, M. S., Santos, M. B. C., \& Pinheiro, T. G. (2015). Representações sociais sobre religião e espiritualidade. Revista Brasileira de Enfermagem, 68(4), 609-616.

Costa, P. C. (2011). A determinação cristológica do ser humano. Atualidade Teológica, 15(39), 503-511.

Dantas, J. G., \& Rodrigues, E. G. B. (2012). A comunicação do Deus neopentecostal: o processo de recepção do discurso midiático da Igreja Universal do Reino de Deus. Protestantismo em Revista, (29), 14-23.

Dias, J. A. (2010). Sacrificium Laudis: a hermenêutica da continuidade de Bento XVI e o retorno do catolicismo tradicional (1969-2009). São Paulo, SP: Editora UNESP/Cultura Acadêmica.

Eliade, M. (2011). História das crenças e das ideias religiosas, volume II: de Gautama Buda ao triunfo do cristianismo. Rio de Janeiro, RJ: Zahar ed.

Faria, J. B., \& Seidl, E. M. F. (2006). Religiosidade, enfrentamento e bem-estar subjetivo em pessoas vivendo com HIV/Aids. Psicologia em Estudo, 11(1),155-164.

Frankl, V. (2007). A presença ignorada de Deus. Petrópolis, RJ: Vozes.

Herzlich, C. (1991). A problemática da representação e sua utilidade no campo da doença. Physis, 1(2), 23-36.

Hiebert, P. G. (2008). Batalha Espiritual e Cosmovisões. Revista Antropos, 2(1), 39-57.

Koenig, H. G. (2012). Religion, Spirituality, and Health: The Research and Clinical Implications. International Scholarly Research Notices Psychiatry, (2012), 1-33.

Koenig, H. G., Pargament, K. I., \& Nielsen, J. (1998). Religious coping and health status in medically ill hospitalized older adults. The Journal of Nervous and Mental Disease, (186), 513-521.

Meneghel, S. N., Farina, O., Silva, L. B., Walter, L. , Brito, S. G., Selli, L., \& Schneider, V. (2008). Histórias de dor e de vida: oficinas de contadores de histórias. Saúde e Sociedade, 17(2), 220-228.

Moreira-Almeida, A., \& Lucchetti, G. (2016). Panorama das pesquisas em ciência, saúde e espiritualidade. Ciência e Cultura, 68(1), 54-57.

Oliveira, D. C., \& Gomes, A. M. T. O processo de coleta e análise dos conteúdos e da estrutura das representações sociais: desafios e princípios para a enfermagem. In M. R. Lacerda, \& R. G. S. Costenaro (Orgs). Metodologias da pesquisa para a enfermagem e saúde: da teoria à prática (pp. 351-386). Porto Alegre, RS: Moriá Editora.

Pecora, A. R. P., \& Sá, C. P. (2008). Memórias e representações sociais da cidade de Cuiabá ao longo de três gerações. Psicologia: Reflexão e Crítica, 21(2), 319-325.

Pontes, A. P. M., Oliveira, D. C., \& Gomes, A. M. T. (2014). Os princípios do Sistema Único de Saúde estudados a partir da análise de similitude. Revista Latino-Americana de Enfermagem, 22(1), 59-67.

Prado, G., Feaster, D. J., Schwartz, S. J., Pratt, I. A., Smith, L. \& Szapocznik, J. (2004). Religious involvement, coping, social support and psychological distress in HIV-soropositive African American mothers. AIDS and Behavior, 8(3), 221-235.

Ratzinger, J. (1970). Introdução ao cristianismo - Preleções sobre o Símbolo Apostólico. São Paulo, SP: Herder.

Ribeiro, D. (1995). O povo brasileiro: a formação e o sentido do Brasil. São Paulo, SP: companhia das Letras.

Rocha, A. C. A. L., \& Ciosak, S. I. Doença crônica no idoso: espiritualidade e enfrentamento. Revista da Escola de Enfermagem USP, 48(Esp. 2), 92-98.

Sá, C. P. (2015). Estudos de psicologia social: história, comportamento, representações e memória. Rio de Janeiro, RJ: EdUERJ.

Silva, C. F. P. (2008). Tensão entre Instituição e Carisma. Revista Theos - Revista de Reflexão Teológica da Faculdade Teológica Batista de Campinas, 4(2), 1-13.

Silva, É. M. P. (2010). Representações sociais da Aids para pessoas que vivem com HIV e suas interfaces cotidianas. Dissertação de mestrado, Universidade do Estado do Rio de Janeiro, Rio de Janeiro, Brasil.

Souza, M. R. (2003/2004). "Ser carismático": as várias faces de um movimento religioso. Antropologia Portuguesa, (20/21), 59-87.

Souza, V. M., Frizzo, H. C. F., Paiva, M. H. P., Bousso, R. S., \& Santos, A. S. (2015). Espiritualidade, religiosidade e crenças pessoais de adolescentes com câncer. Revista Brasileira de Enfermagem, 68(5), 791-796. 
Valle, J. E. R. (2005). Religião e espiritualidade: um olhar psicológico. In M. M. Amatuzzi (Org). Psicologia e espiritualidade (pp. 78-110). São Paulo, SP: Paulus.

Vergès, P. (1994). Approche du noyau central: propriétés quantitatives et structurales. In: C. Guimelli (Org.). Structures et transformations des représentations sociales (pp. 233-253). Neuchâtel: Delachaux et Niestlé.

Apresentação: 01/10/2016

Aprovação: 30/11/2016 